\title{
Exploring the Suitability of Handheld Devices for Mobile Learning
}

\author{
Olutayo Boyinbode ${ }^{1}$ and Tolulope Ogundipe ${ }^{2}$ \\ ${ }^{1,2}$ Department of Computer Science \\ Federal University of Technology, Akure, Nigeria \\ okboyinbode@gmail.com ${ }^{1}$,tolupe@gmail.com ${ }^{2}$
}

\begin{abstract}
The proliferation of smart and mobile devices in our daily activities has also crept into our education all around the world. The most important benefit of these devices is the fact that they are absolutely mobile and can be taken and used anywhere at any place any time. Mobile learning is one of the ways that learning can be extended and it is easily accepted in our modern times since network and phone are readily available. With the rapid development of mobile computing technologies, a new style of learning (Mobile Learning) has exploded all over the world. The availability and suitability of handheld devices encourages learning for individual or learner on the move. This paper evaluates what type of handheld device is most suitable for mobile learning using a set of criteria. It also involves the development of a mobile application, and analysing learners' experiences based on their handheld devices.
\end{abstract}

Keywords: Mobile learning, handheld devices, User interface Media, Navigation, Presentation, Battery life, Handiness

\section{Introduction}

One of the biggest trends in the world today is the shift from big super computers to small handheld devices that use the latest technologies with increasingly powerful processors and more advanced operating system. The proliferation of these devices is evident in our daily activities $[1,3]$. These technologies have been adopted in educational systems all around the world. The need for learning not to be stereotyped to the classroom has brought about the initiative of mobile learning [2-4, 12]. Mobile learning offers methods which decrease the limitations of traditional education and offer good supplement to classroom learning. The evolutions of handheld portable devices and wireless technology have resulted into radical changes in the social and economic lifestyles of modern people. Today, many technological devices are produced in portable form and people have become accustomed to using them [4]. These devices are already reshaping users' daily lives in different ways, but the development of digital technologies has so far been limited to social communication and few people have regarded mobile learning as a core pedagogical activity in higher institutions of learning. The popularity of these devices is a consequent of their ability to function at multiple levels $[15,16]$. Today's mobile devices are functional devices capable of providing a broad range of applications for both business and education [11].

The popularity of mobile technologies among college students is increasing dramatically. Many undergraduate students own and bring their own mobile devices to college [7, 9, 13-14], favouring small and portable ones such as smart-phones, ipad and tablets. Although some students still rate their laptops as being crucial to their academic success, the importance of mobile devices such as tablets, smart-phones and ipad is noticeably on the rise [4]. Increasingly, students say they want to access academic resources on their mobile devices. Many of students' smart phones and tablets are being 
used for learning purposes [7]. Classroom learning occurs within a fixed location; Survey showed that most students of tertiary institution prefer using mobile devices for learning as a supplement to the classroom learning, this happened because handheld devices were suitable for accessing information on the go at any time or anywhere and they were easy to carry around [16-17].It was recommended based on the findings of the research that government should motivate and encourage both students and their lecturers to incorporate the use of mobile technologies for learning in Universities as a whole [16].

The idea of a stereotypical way of learning in fixed classrooms and environment have been attempted to be solved countless of times. People have tried to implement new ways of bringing diversity into the way and how we learn. They have created mobile and elearning applications to explore how learning can be supported across contexts, how mobile devices enable conversations for learning and how new methods of evaluation can reveal the outcomes of learning outside traditional and fixed setting or environment [14]. These researches although very insightful have failed to adequately evaluate what type of device would be most suitable for learning by focusing on the usability. The design of mobile technology for learning has much to learn from interaction design research [10], which offers general principles for human-computer interaction on mobile devices. Issues regarding the features of mobile devices - usability, technical and functional - are indeed very important to be resolved $[5,-6,8,10]$. This paper is aimed at evaluating the suitability of some mobile devices for learning in terms of suitability, interface, security, battery life etc. This paper evaluates the various types of handheld devices and deduces the most suitable device for mobile learning.

\section{Handhelds and Usability}

Most times, students use their handheld devices in any situation while on the move and they should be able to comfortably access and use the devices to accomplish learning tasks. Therefore, the interface layout, toolbars, buttons should facilitate ease of use for the learner. It should make learning easier for averagely tech-orientated individuals [13]. Manufacturers of most mobile devices have over time tried to improve the appearance of their devices either through their size, weight, speed or input method. Simultaneously, handheld devices should be friendly to people with special needs giving them the opportunity to participate in educational activities. This could be possible by incorporating text-to-speech or voice recognition feature. It would be helpful for each learner to be able to personalise each device to their liking and educational activity.

Some handheld devices, especially the recently made smart phones, solve the navigation problem combining the mouse and the keyboard in one device, the touchscreen. The touch-screen facilitates the student to navigate the menu and sub-menus easier finding the target file or tool immediately. In contrast to the touch screen smart phones, some devices do not support touch-screen but give to the student a five-direction pad as an alternative way to navigate. The usability criteria adopted in this paper involve the following sub-themes: User interface, Media, Navigation, Presentation, Battery life and Handiness [8].

\section{Methodology}

This research was carried out within a confined observation ground; the Federal University of Technology, Akure. The phases involved in this project are listed below:

i. Development of a mobile learning application which cut across several platforms like Android, Windows etc.

ii. Setting up the application on the phones of the volunteers.

iii. Evaluate their experience with the application and their device through the use of a questionnaire. 
The present framework is quite simple and straightforward and so is applicable to any higher education system. However, the framework was specifically designed for the evaluation of handheld devices for learning and contains the basic features that would ensure the successful evaluation in the research.

\subsection{Data Analysis}

This project research was carried out by gathering data and information from both primary and secondary sources respectively. Data was gathered primarily with the use of questionnaires, personal observations and interviews. Three different forms of questionnaire were administered during the course of this project. The first form of questionnaire had to do with what role their mobile devices play in their day to day activities. The second part of the questionnaire had to do with people's perception about mobile learning. The third part had to do with the appropriateness of their devices for learning and how does it support their learning activities in relation to usability, screen size, battery life, autonomy etc.

A total number of 120 students with different handheld devices produced by various manufacturers took part in using the mobile application and taking part in the survey. The survey were carried out in two forms; the first one being an online survey using a web based application known as Google forms. This online survey was incorporated into a mobile learning application that was created for the purpose of this research work. The application was designed to get an accurate measure of what device is most suitable for learning; the application was suited to each mobile platform. Video interviews were also carried out while people were interacting with the mobile application on their devices to get the perspective of the usability of their devices.

\subsection{Research Ethics}

The respondents of the different questionnaire have been assured of confidentiality regarding information provided. Therefore, the confidential information collected during the course of this research will not be documented. In the course of administering the questionnaire, an interview was conducted for a few people to be able to distinctively analyze their responses and determine if there was a varying response from those filling the survey.

The categories of people that filled the research questionnaires includes: undergraduate students, post graduate student and various working class individuals from different institutions and organizations. The data was analyzed using Google Forms and its mathematical analysis known as the Google Spreadsheet. Aside mathematical analysis, the Google spreadsheet is also used for educational research, survey analysis, market research etc.

\subsection{Research Procedure}

For the purpose of this project, I invited over two hundred (200) students for this research and got responses from about 120 students most of which are students in 100 and 500 levels, who are currently offering the GNS 106 (General Studies) and the MEE 102 (Mechanical Engineering) courses in the Federal University of Technology, Akure. Data were collected from the course outline of MEE 102 and audio data recorded from the course content of GNS 106 were uploaded to the mobile learning application.

A meeting was arranged such that the respondents can use the application together in a classroom. After the course has been taken, the respondents took a small quiz to test their knowledge. Right after the assessment, is an online survey which evaluates their learning experience on their devices. 


\subsubsection{Components of the Mobile Application}

The mobile application, a web based application was developed using Java programming language on Eclipse and Phone gap. Eclipse contains a base workspace and an extensible plug-in system for customizing the environment. Phone gap is a mobile development framework that enables software programmers to build applications for mobile devices using JavaScript, HTML5, and CSS3, instead of relying on platformspecific APIs like those in iOS, Windows Phone, or Android. The main factor of consideration while designing the mobile learning application; is its simple accessibility with minimum requirements. On the user side, due to varying screen size, battery, communication technologies, and accessibility etc. the application is implemented to fit the devices specification on framework stated above. The application was ported to other platforms, the apk was distributed via various file sharing manager like Bluetooth and Xender.

The application has a list of courses where the student can choose a course of interest from, though only GNS 106 and MEE 102 courses were loaded for this project. This application provides a quick description for each syllabus in a course so that the students can prepare ahead of the class. It uses a community-based platform that aids interaction and communication between instructors and students taking the course. It provides the opportunity to test the knowledge of each learner before and after a course is taken.

\subsection{Data Result and Implementation}

After the successful completion of each course on the mobile application, the user is prompted to take part in the evaluation of their devices and their experiences obtained during the course of their study. In some other cases, the evaluation data was filled offline in a printed paper after the successful completion of the courses.

Figure 1.1 shows a summarized copy of the course content of MEE102. The picture shows the importance of user interface design and experience. It uses a convenient and friendly colour which has been known to improve student's learning on mobile [17].

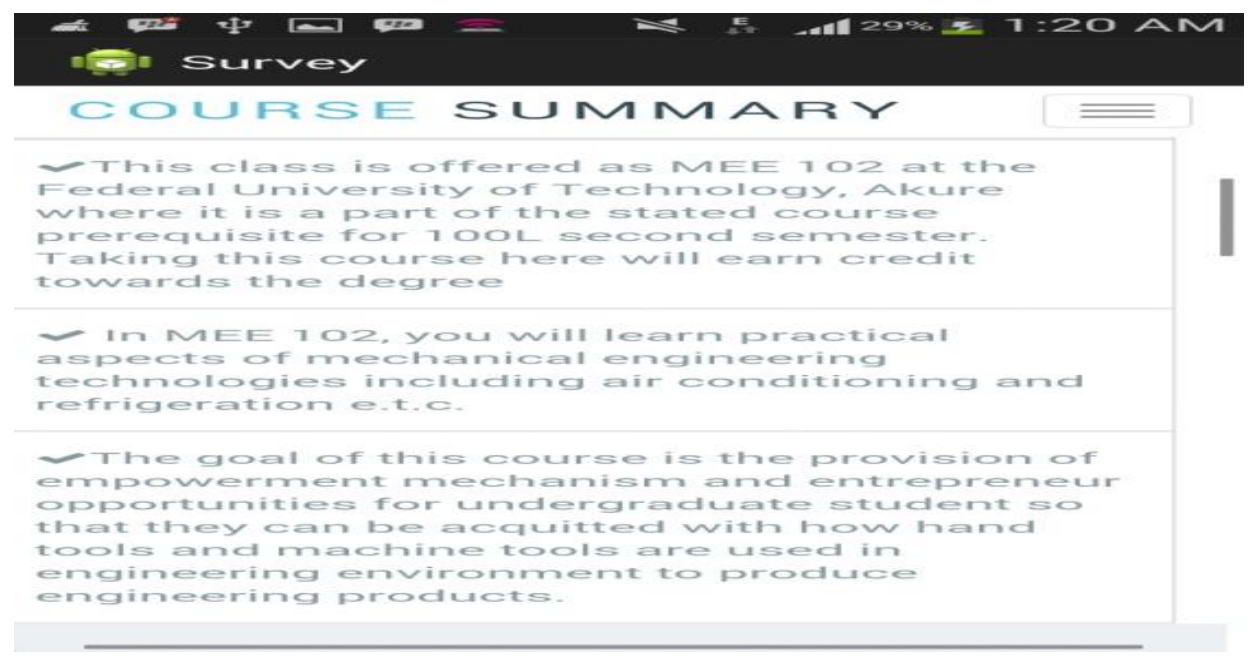

Figure 1.1. Depicts the Course Summary and what to Expect in the MEE 102 Content

The Figure 1.2 below also shows a course preparation page that prepares the user for what they should expect in the course, It also shows the course requirement i.e. if prior knowledge is required. This application also tests the preparedness of the user or student for taking the course. This means that it checks if the user has and can spare the required 
length of time and components to take the course. The required components could be time, unlimited access to internet, a working mobile phone etc.

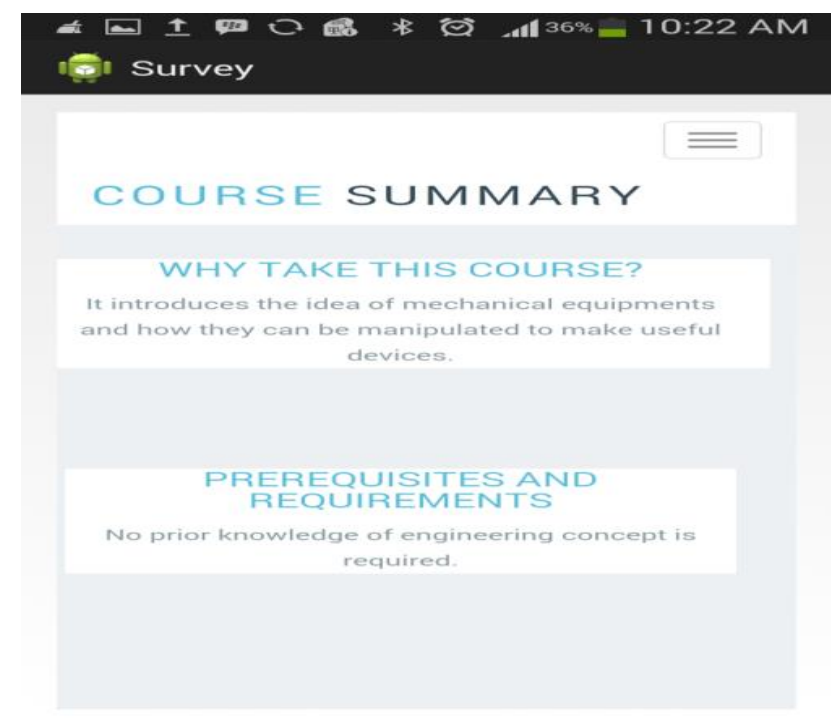

Figure 1.2. Depicts the Requirements and Prerequisite for Taking the Course

Figure 1.3 below shows the course syllabus on the android application. The syllabus also shows a summarized version of the course before the user starts learning. It shows the topics and content to expect from the course. It buttresses the course summary and depicts a breakdown of the course as it progresses.

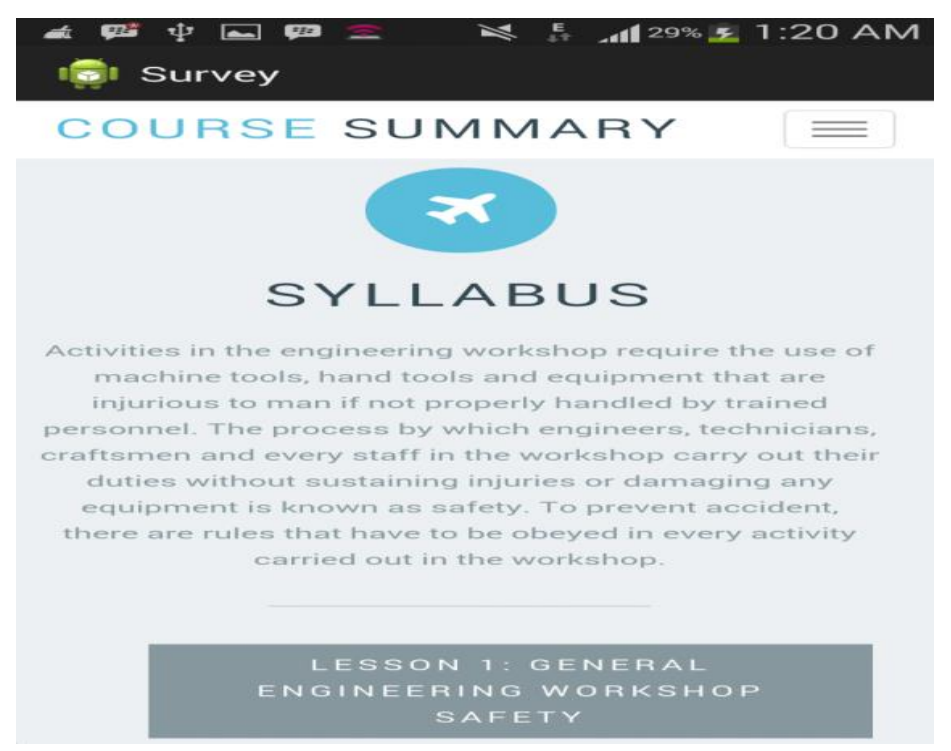

Figure 1.3. Depicts the Syllabus and Course Outline of MEE 102

Figure 1.4. Shows the safety precautions which must be followed as related to MEE102. 


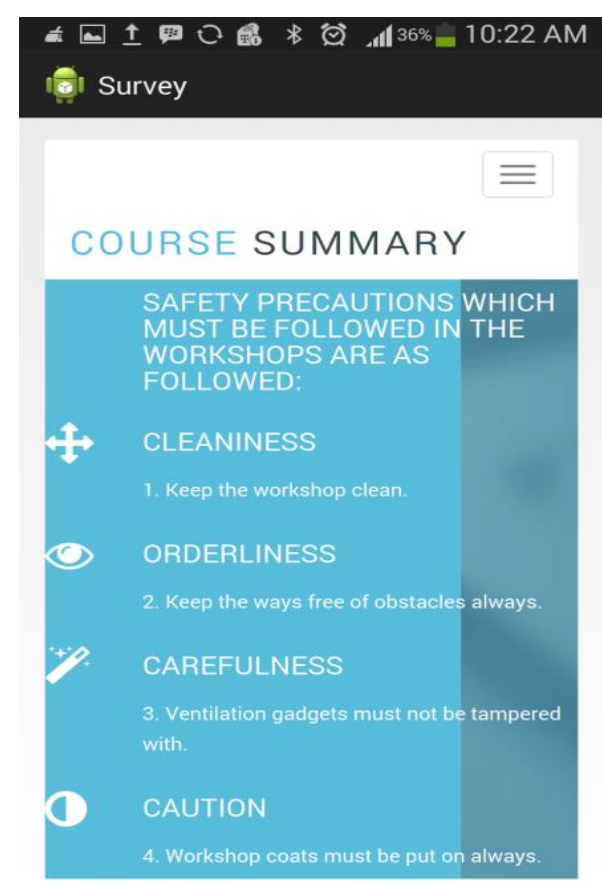

Figure 1.4. Depicts the Course Summary of MEE102

\subsubsection{Mobile Learning Application Interface on Various Mobile Platforms}

This section (Figure 1.5, 1.6, 1.7) shows some students using the android application on different mobile devices.

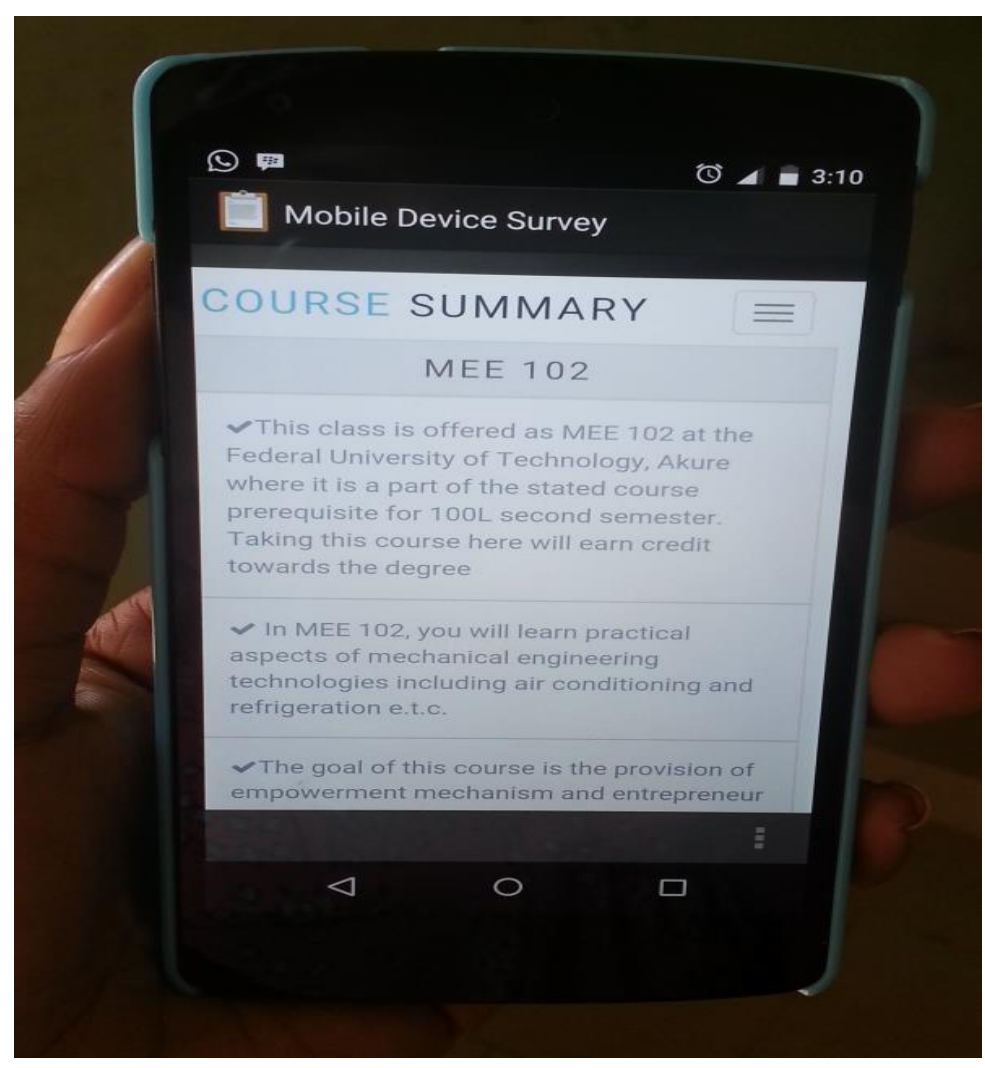

Figure 1.5. Shows a Student Learning on her Nexus Mobile 


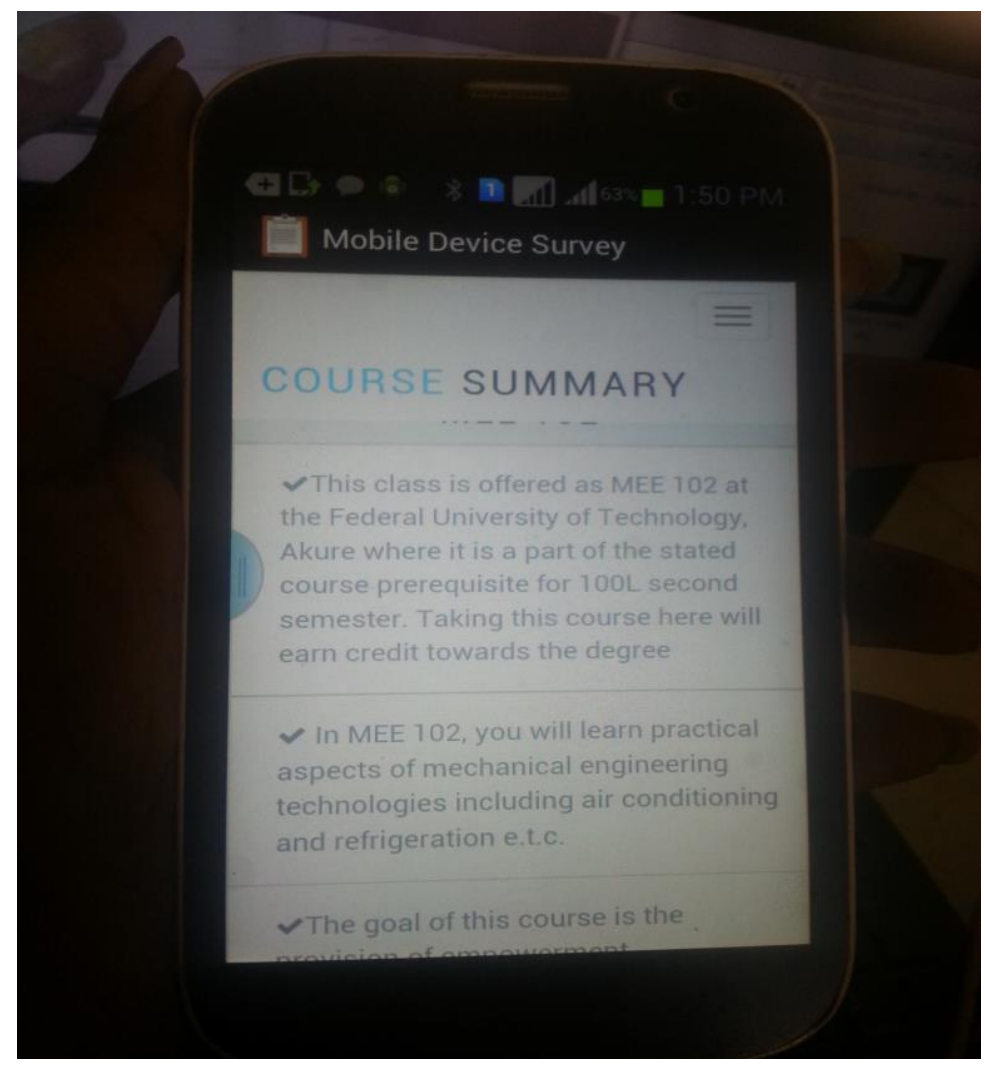

Figure 1.6. Depicts the Application on a Samsung GT 198 Mobile

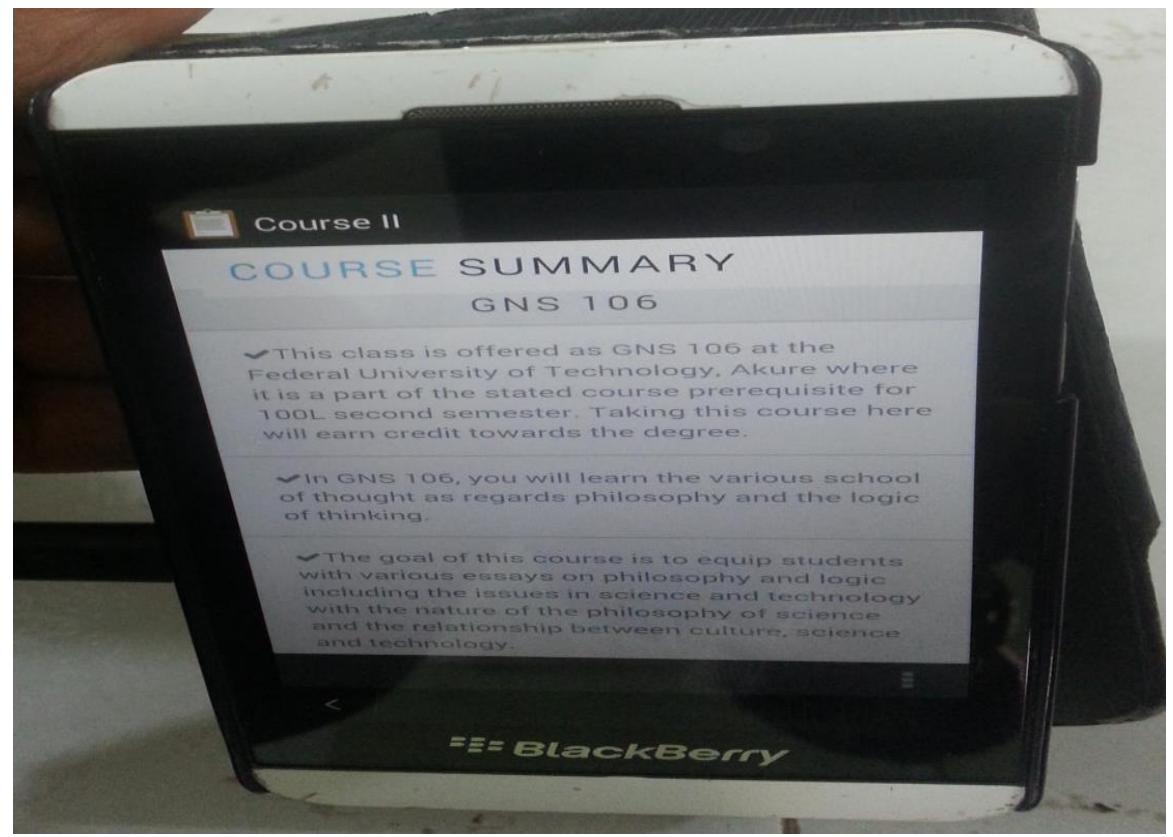

Figure 1.7. Shows a Snapshot of the App on a Blackberry Z10 Mobile

\subsubsection{Assessment/Quiz Test}

After the contents; comes a quiz or mini-examination that tests the student's knowledge after reading and understanding the course. Figure 1.8 shows the assessment test page, where the learners' test their learning ability after reading through the course 
content. Figure 1.9 and Figure 2.0 depict the online survey that comes up immediately after taking the course and the quiz.

$\begin{aligned} & \text { Which of the following group of } \\ & \text { people have not attempted to } \\ & \text { define philosophy as stated } \\ & \text { above? }\end{aligned}$
$\begin{aligned} & \text { What did Okponaviobo say about } \\ & \text { human beings as regards } \\ & \text { philosophy? }\end{aligned}$
$\begin{aligned} & \text { Those involved in meditation } \\ & \text { and contemplation. }\end{aligned}$
Those interested in wisdom
All human beings are thinkers
Rational Thinkers.

Figure 1.8. Depicts a Page that Shows the Assessment Test Page

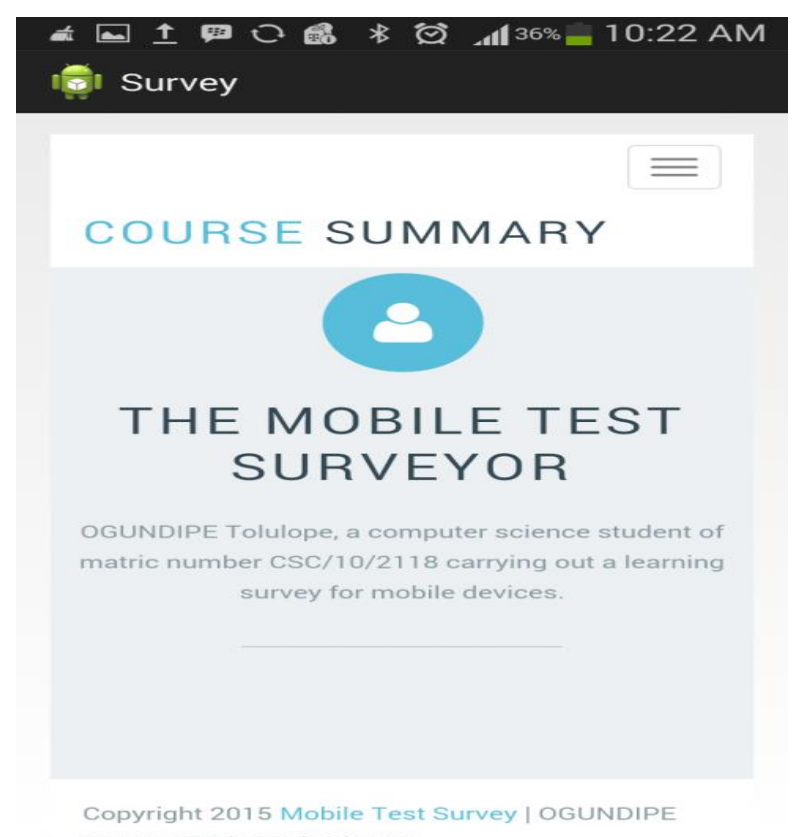

Figure 1.9. Shows the Mobile Test Surveyor 
Evaluating handheld Devices for Mobile learning

Hello,

My name is Tolulope Ogundipe. A

student of Computer Science Department at the Federal University of Technology, Akure. Am currently running a survey to most suitable for learning. This survey is in line with my final year project which is required for the successful completion of my Bachelors Degree.

Kindly keep in mind that this is strictly

for research purposes. All data and

information collected will be highly

confidential and used judiciously.

Thanks and Cheers.

* Required

Do you own a mobile device? *

$\cap$ Yes
3 hours

3-5 hours

6-10 hours

11-14 hours

Other:

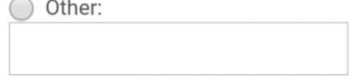

Have you ever used your device for learning?*

Yes

No

Kindly tick as appropriate the mobile device you have used. *

Amazon Kindle

Samsung mobile

Samsung tablet

Nokia mobile

Nokia tablet

Techno mobile

Figure 2.0. Online Survey

The user is prompted to take a survey which tests their usability experience with the application in relation to their various devices. This test surveyor takes them to a Google form page that evaluates the users' device for learning on the application. The test surveyor evaluates the suitability of learning on each of those devices as used by the students.

\subsubsection{Analysis of Responses}

In analysing the data collected from the survey, descriptive statistics have been used as a means of analysing information collected through questionnaire administration.

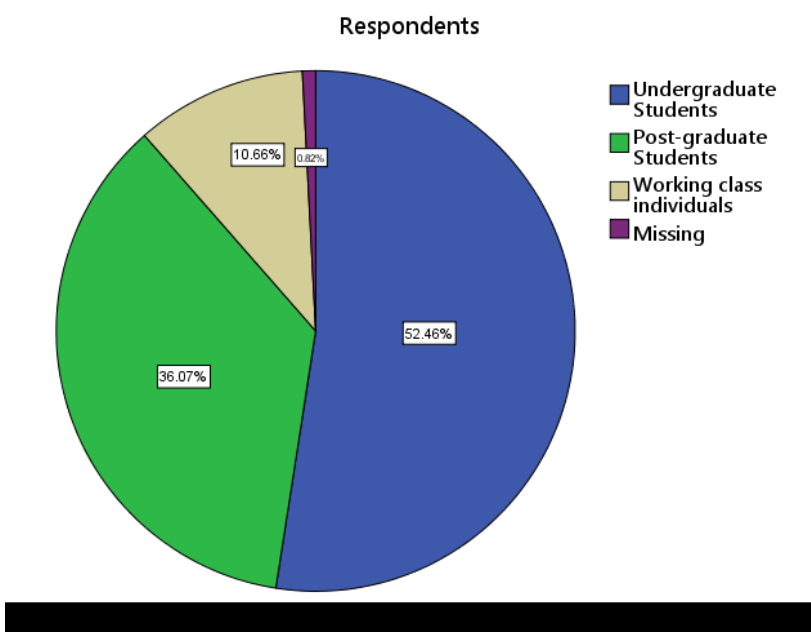

Figure 2.1. Graphical Representation of Respondent 
From Figure 2.1, the graphical representation above, the result recorded that undergraduate students were $52.46 \%$ while $36.07 \%$ responses were gotten from postgraduate students and a $10.66 \%$ were recorded from working class individuals.

\subsubsection{Device Type}

From this survey Blackberry mobile and Samsung mobile appeared more frequently in the three groups of individual that responded to the survey with 19 and 17 respondents respectively. From the total number of about 120 devices that were evaluated, about $15.7 \%$ of the devices were Samsung mobile followed by a $14 \%$ from Blackberry mobile and a $11.6 \%$ from Techno mobile etc. (see Figure 2.2)

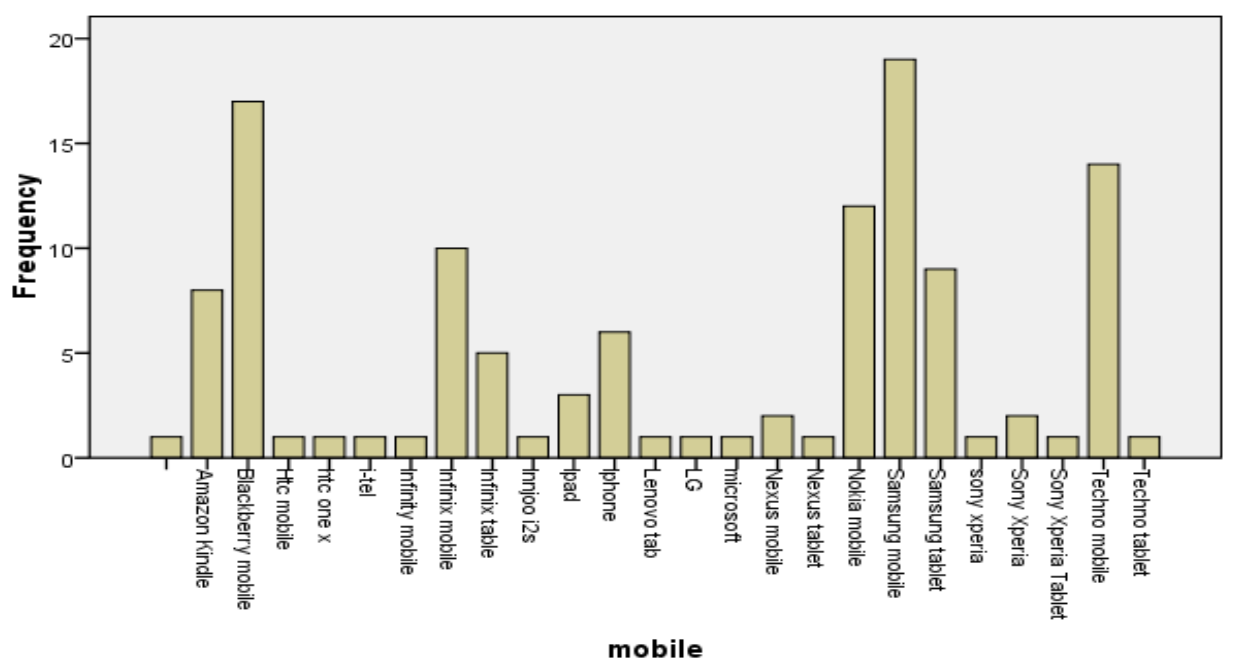

Figure 2.2. Shows a Graphical Representation of Devices

The picture above depicts a descriptive analysis of the devices that were involved in this research. It was recorded that Samsung mobile had more users followed by Blackberry mobile.

\subsubsection{Battery Life Autonomy}

Battery life is a major determinant of an effective learning on handheld devices; since it is an anywhere and anytime form of learning. Previous research works have also stated the importance of battery life. The ability of the handheld device to go through the whole course without shutting down is an added advantage to mobile learning. From Figure 2.3, Most of the devices, recorded a 6-10 hours of battery life, as the highest followed by the 3-5 hours with 46 and 30 respondents respectively. 


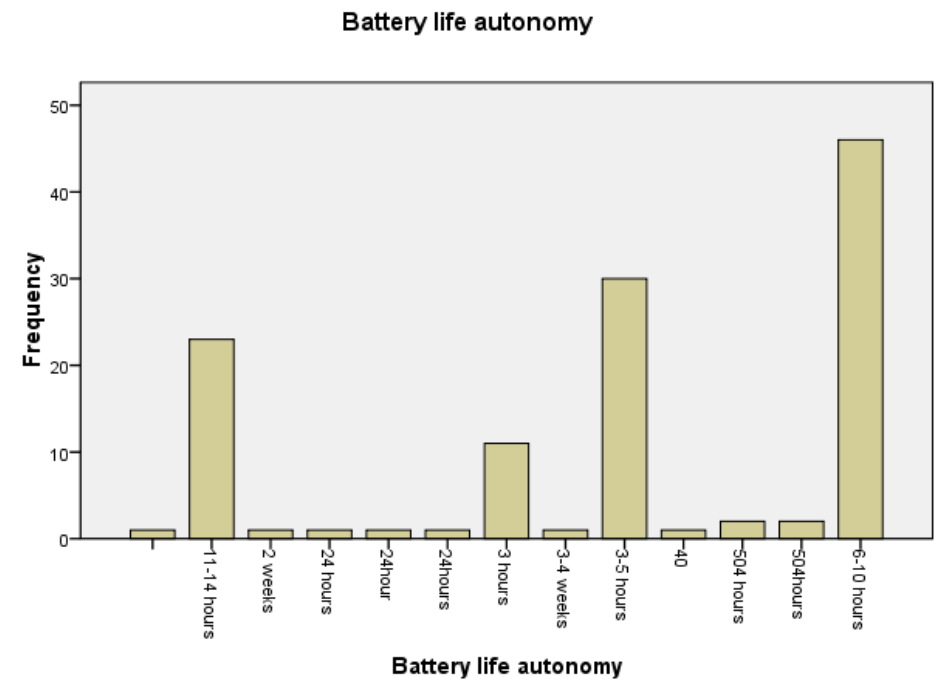

Figure 2.3. Battery Life Autonomy

\subsubsection{Operating Systems}

From Table 1 and Figure 2.4 shows the distribution of various operating systems among current devices that were recorded. Android O.S. is the most popular and is supported by over $66.9 \%$ of the devices, followed by Blackberry OS with $12.4 \%$ and Windows by $9.9 \%$.

Table 1. Operating System

\begin{tabular}{|c|c|c|c|c|}
\hline & Frequency & Percent & Valid Percent & Cumulative Percent \\
\hline Valid & 1 & .8 & .8 & .8 \\
\hline Android & 81 & 66.9 & 66.9 & 67.8 \\
\hline black berry & 1 & .8 & .8 & 68.6 \\
\hline BlackBerry & 1 & .8 & .8 & 69.4 \\
\hline Blackberry OS & 15 & 12.4 & 12.4 & 81.8 \\
\hline Firefox OS & 1 & .8 & .8 & 82.6 \\
\hline IOS & 9 & 7.4 & 7.4 & 90.1 \\
\hline Windows & 12 & 9.9 & 9.9 & 100.0 \\
\hline Total & 121 & 100.0 & 100.0 & \\
\hline
\end{tabular}




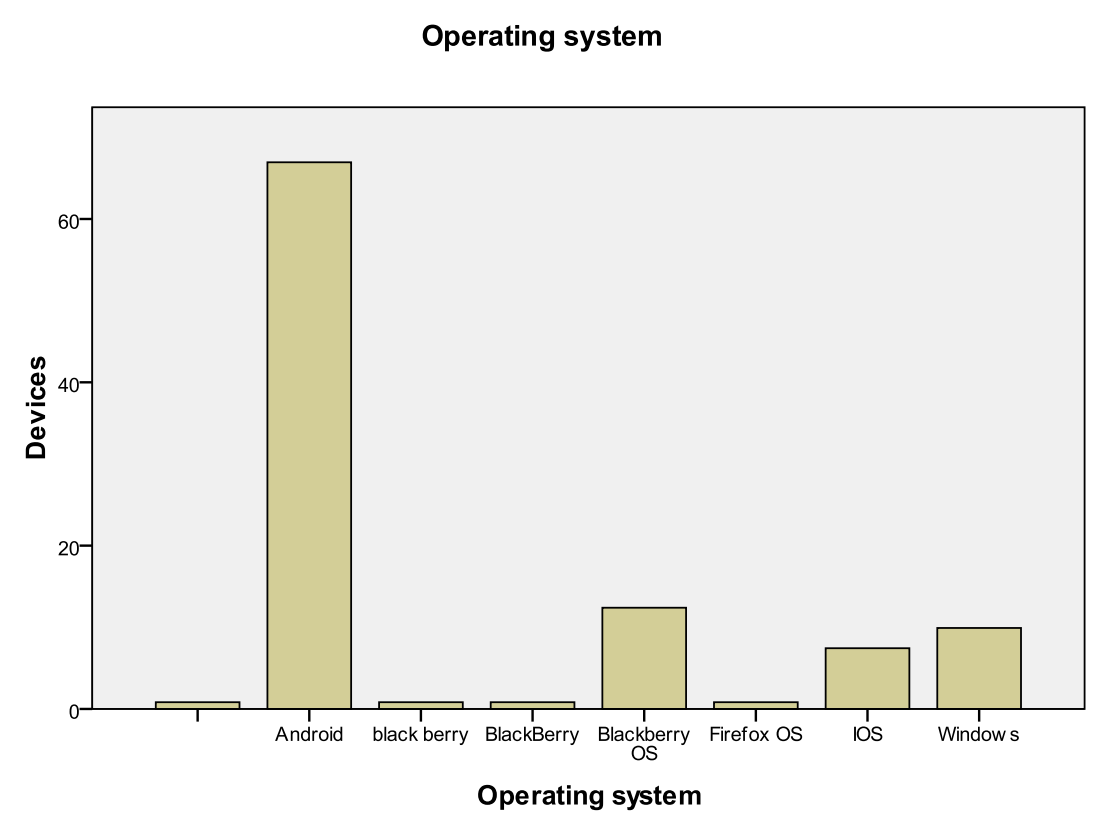

Figure 2.4. Operating System Distribution

\subsubsection{Device Memory Size}

From Table 2 and Figure 2.5 shows the distribution of the phone memory sizes used by the devices. Most devices use a size between 2 and 4 GB (45 devices), followed by 1631GB (31 devices) and 8-15GB (23 devices). Only few devices use sizes 32-64 GB. This indicates that most students own and prefer a handheld device with over 4GB of storage for storing learning information.

Table 2. Device Memory Size

\begin{tabular}{|c|l|l|l|l|}
\hline & Frequency & Percent & Valid Percent & Cumulative Percent \\
\hline Valid 16-31 GB & 31 & 25.6 & 25.6 & 25.6 \\
2-4 GB & 45 & 37.2 & 37.2 & 62.8 \\
$32-64 \mathrm{~GB}$ & 7 & 5.8 & 5.8 & 68.6 \\
$5-7 \mathrm{~GB}$ & 15 & 12.4 & 12.4 & 81.0 \\
$8-15 \mathrm{~GB}$ & 23 & 19.0 & 19.0 & 100.0 \\
Total & 121 & 100.0 & 100.0 & \\
\hline
\end{tabular}




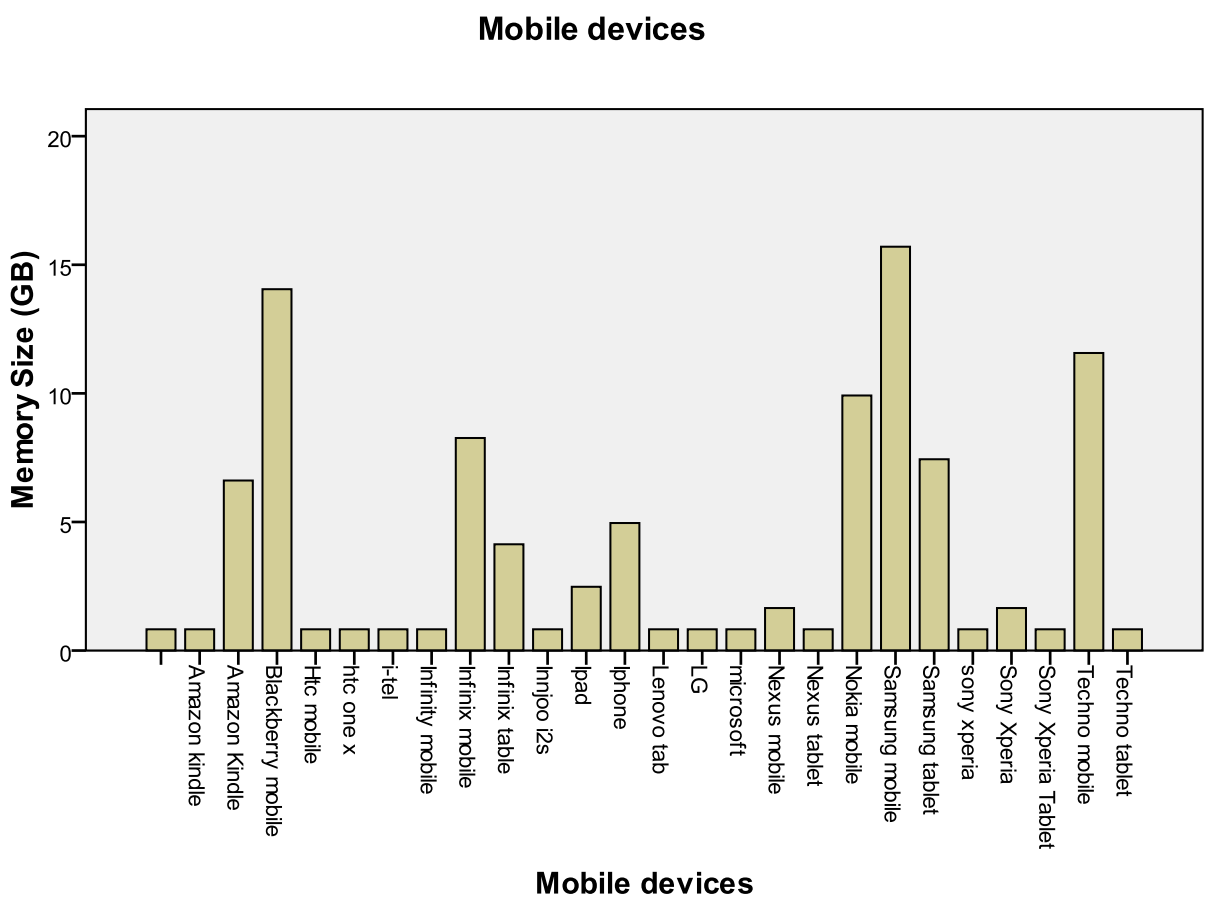

Figure 2.5. Shows the Graphical Representation of the Devices Against their Memory Sizes

\subsubsection{Screen Size Distribution}

Screen size is surely a major concern to all users that make use of their devices for learning. Handheld devices have varying screen size and each user has a personalised perspective on how their screen size affects their learning on mobile. Table 3 and Figure 2.6 depicts the screen size distribution of the devices in the survey. $67.8 \%$ of the students with 5"-7" screen size indicated their devices as highly suitable for mobile learning.

Table 3. Screen Size Distribution

\begin{tabular}{|c|l|l|l|l|}
\hline & Frequency & Percent & Valid Percent & Cumulative Percent \\
\hline Valid 3"- 4" & 23 & 19.0 & 19.0 & 19.0 \\
$4.7 "$ & 1 & .8 & .8 & 19.8 \\
$5 "-7 "$ & 82 & 67.8 & 67.8 & 87.6 \\
$9 "-11 "$ & 15 & 12.4 & 12.4 & 100.0 \\
Total & 121 & 100.0 & 100.0 & \\
\hline
\end{tabular}




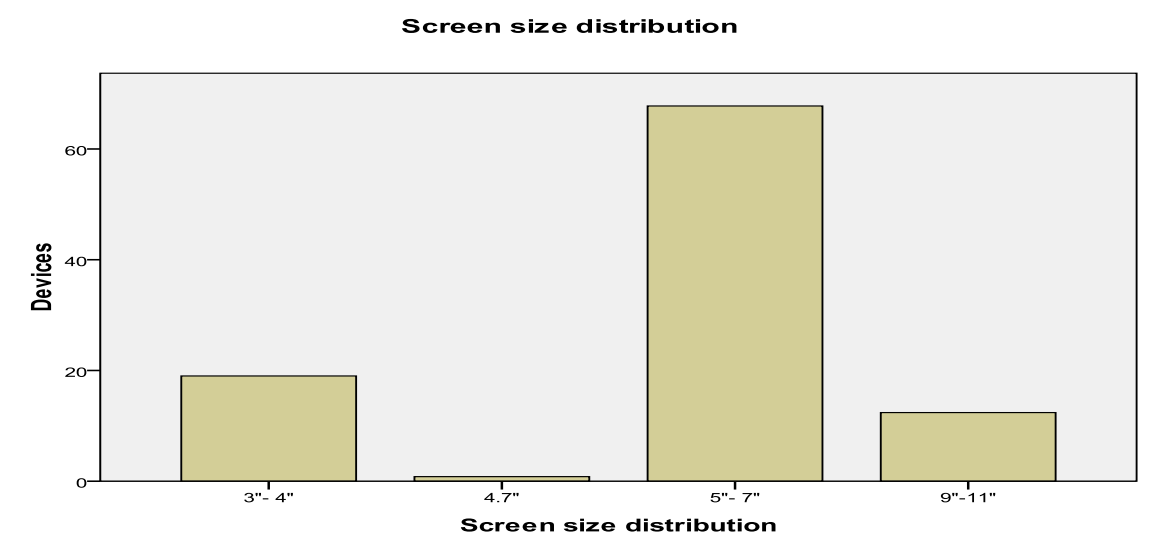

Figure 2.6. Shows the Screen Size Distribution of the Devices

\subsubsection{Handiness}

Table 4 and Figure 2.7 depict the handiness of the devices. Handiness means easy to carry about. $80-100 \%$ of the students indicated their devices as very handy.

Table 4. Handiness

\begin{tabular}{|c|l|l|l|l|}
\hline & Frequency & Percent & Valid Percent & Cumulative Percent \\
\hline Valid & 2 & 1.7 & 1.7 & 1.7 \\
$0-20 \%$ & 6 & 5.0 & 5.0 & 6.6 \\
$20 \%-40 \%$ & 14 & 11.6 & 11.6 & 18.2 \\
$50 \%-70 \%$ & 8 & 6.6 & 6.6 & 24.8 \\
$50 \%-70 \%$ & 28 & 23.1 & 23.1 & 47.9 \\
$80 \%-100 \%$ & 63 & 52.1 & 52.1 & 100.0 \\
Total & 121 & 100.0 & 100.0 & \\
\hline
\end{tabular}

Handiness i.e. easy to carry

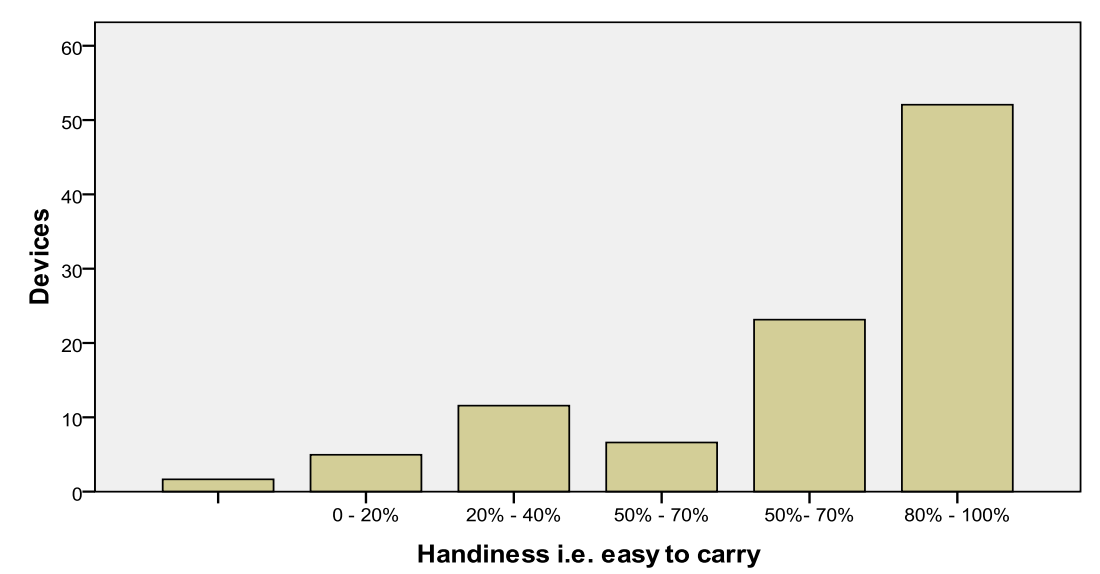

Figure 2.7. Shows the Handiness of the Devices in Relation to the Devices 


\subsubsection{Presentation and Media}

Table 5 and Figure 2.8 depict the presentation and media of the devices. 50\%-70\% of the students recorded their devices as having very good presentation and media formats.

Table 5. Presentation and Media

\begin{tabular}{|c|r|r|r|r|}
\hline & Frequency & Percent & Valid Percent & Cumulative Percent \\
\hline Valid & 2 & 1.7 & 1.7 & 1.7 \\
$0-20 \%$ & 9 & 7.4 & 7.4 & 9.1 \\
$20 \%-40 \%$ & 14 & 11.6 & 11.6 & 20.7 \\
$50 \%-70 \%$ & 4 & 3.3 & 3.3 & 24.0 \\
$50 \%-70 \%$ & 49 & 40.5 & 40.5 & 64.5 \\
$80 \%-100 \%$ & 43 & 35.5 & 35.5 & 100.0 \\
Total & 121 & 100.0 & 100.0 & \\
\hline
\end{tabular}

Presentation and Media

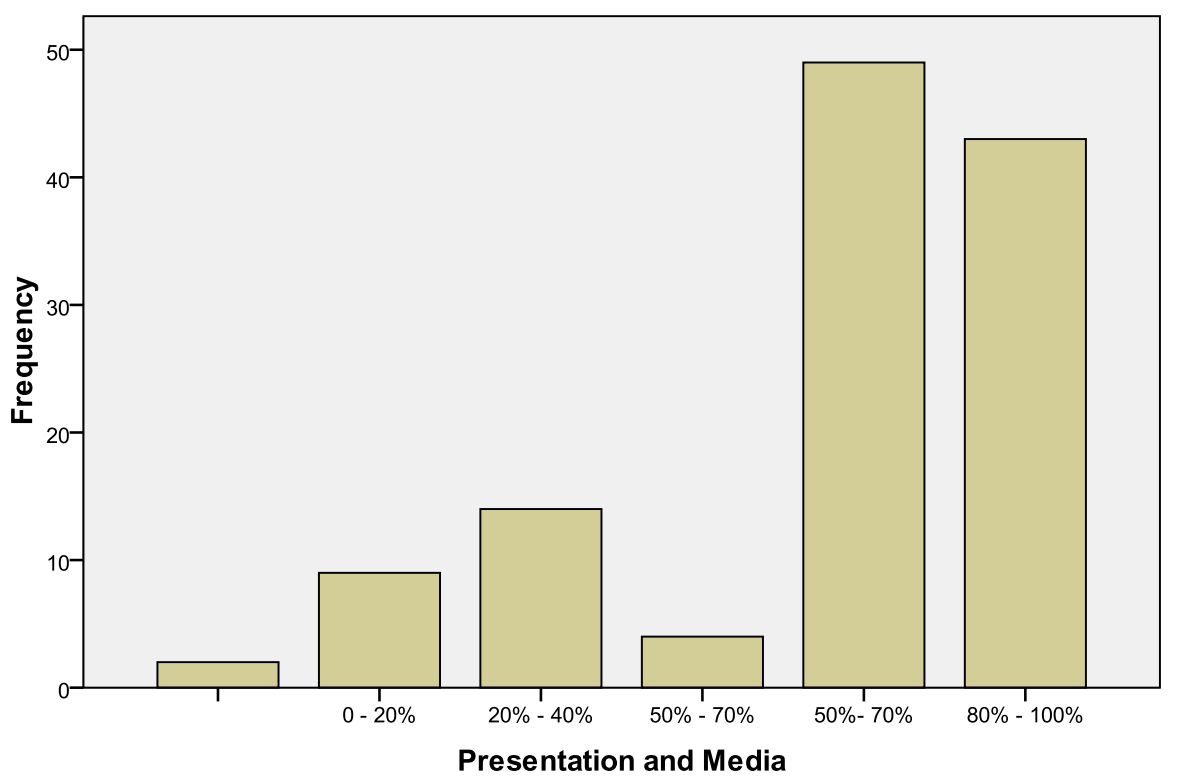

Figure 2.8. Depicts a Graphical Representation of Presentation and Media

\subsubsection{Navigation}

Table 6 and Figure 2.9 depict navigation of the devices. 80\%-100\% of the students recorded their devices as having very good navigation. 
Table 6. Navigation

\begin{tabular}{|l|r|r|r|r|}
\hline & Frequency & Percent & Valid Percent & Cumulative Percent \\
\hline Valid & 2 & 1.7 & 1.7 & 1.7 \\
$0-20 \%$ & 9 & 7.4 & 7.4 & 9.1 \\
$20 \%-40 \%$ & 16 & 13.2 & 13.2 & 22.3 \\
$50 \%-70 \%$ & 5 & 4.1 & 4.1 & 26.4 \\
$50 \%-70 \%$ & 42 & 34.7 & 34.7 & 61.2 \\
$80 \%-100 \%$ & 47 & 38.8 & 38.8 & 100.0 \\
Total & 121 & 100.0 & 100.0 & \\
\hline
\end{tabular}

\section{Navigation}

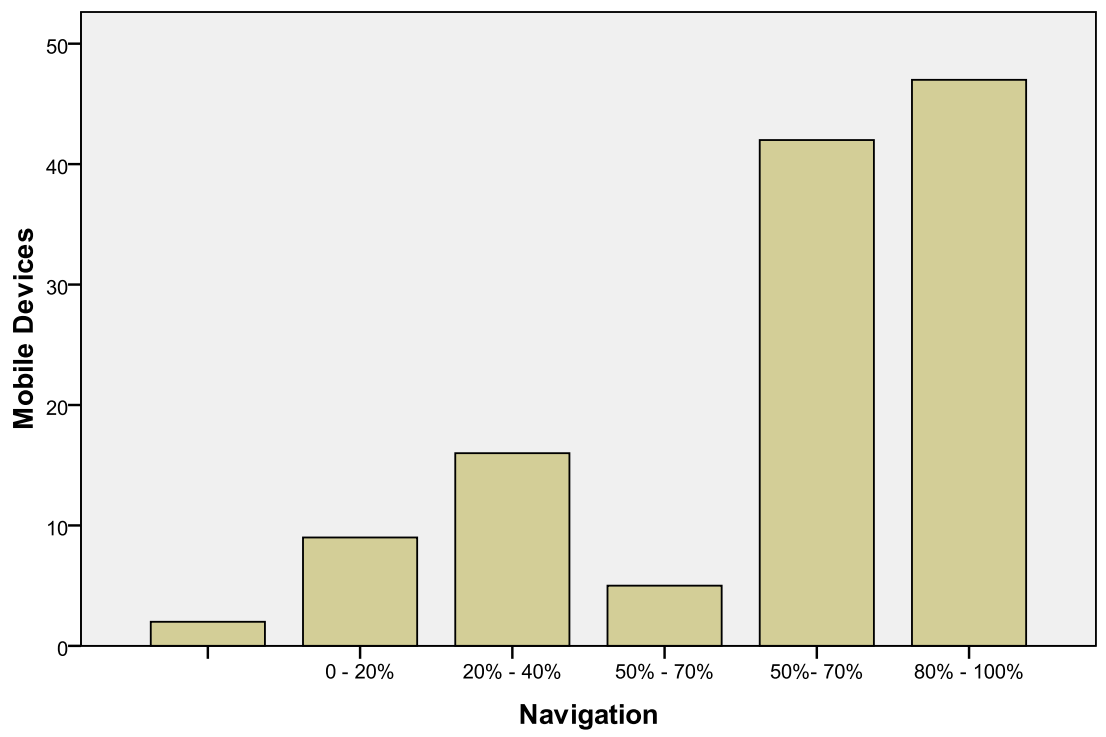

Figure 2.9. Depicts the Ease of Navigation in Relation to the Mobile Devices

As the analysis above has shown, we have been able to evaluate a number of devices for the purpose of evaluating their suitability for learning. Other research works have stated the importance of some of these features for learning and according to this research; we have been able to validate the effectiveness of some of these features. It is important to follow the trend in mobile technology for learning, it is also important to put little things like screen size, battery life, presentation and media, access to organisation and management etc. into consideration. These features actually improve and encourage effective learning on handheld devices.

\section{Conclusion}

The most important benefit of handheld devices is the fact that they are absolutely mobile and can be taken and used anywhere at anyplace any time. It has been stated that the learning processes must be flexible and robust to be able to withstand lifelong learning. Mobile learning is one of the ways that learning can be extended and it is easily accepted in our modern times since network and phone are readily available. In this 
research, various devices have been reviewed to highlight the features that work best. We noticed that most people in this school environment (FUTA) use devices that run on Android with an exaggerated focus on screen size, battery life, memory size and user interface. As much as these features are somewhat apparent, there are still features that can be improved and worked on by manufacturers or put into consideration by school authorities. According to this research, it was obvious that students prefer a five inches and above screen size for learning, they also prefer a device with a very good user interface, preferably screen touch for easy organisation and management, access to information and knowledge and very good battery life. When asked what devices the respondents prefer, they would rather use a Samsung mobile for learning and this is because of its long battery life, ease of navigation, presentation and media. Most of the available Samsung devices had a screen size of five inches and above which means there is a larger screen surface area that enhances learning. Most of these devices are also really easy to carry about which is attributed to handiness. They also preferred this device because of the battery life when not connected to the internet. They had an average of six to ten hours battery life. This device also had a very good presentation and media in relation to its user interface. This means that it is very easy for its users to interact with it.

\section{References}

[1] M. V. Adegbija and O. O. Bola, "Perception of undergraduates on the adoption of mobile technologies for learning in selected universities in Kwara state, Nigeria", Procedia-Social and Behavioral Sciences, vol. 176, (2015), pp. 352-356.

[2] I. A. Alshalabi and E. Abdelfattah, "Management of Multimedia in E-Learning Environments", American Society of Engineering Education North East Conference, Boston, MA, (2010).

[3] M. Beale, "Pocket University: Mobile learning in distance education", Learning Technology Newsletter, (2007).

[4] S. Bidin and A. A. Ziden, "Adoption and application of mobile learning in the education industry", Procedia-Social and Behavioral Sciences, vol. 90, (2013), pp. 720-729.

[5] D. Becking, S. Betermieux, B. Bomsdorf, B. Feldmann, E. Heuel, P. Langer and G. Schlageter, "How to match mobile learning resources with learners current needs: The didactic profiling", Proceeding HCII2005, vol. 144, (2005).

[6] B. Yan, S. Mao and L. Ruan, "Research on E-Learning and its related issues, Computer Science and Information Technology (ICCSIT)", 2010 3rd IEEE International Conference on, vol. 8, (2010), pp. 331-334.

[7] O. K. Boyinbode and R. O. Akinyede, "Mobile learning: An application of mobile and wireless technologies in Nigerian learning system", International Journal of computer science and network security, vol. 8, no. 11, (2008), pp. 386-392.

[8] A. A. Economides and N. Nikolaou, "Evaluation of handheld devices for mobile learning", International Journal of Engineering Education, vol. 24, no. 1, (2008), pp. 3.

[9] V. F. Martinez, J. Virseda and A. Gomero, "Mobilizing education: evaluation of a mobile learning tool in a low-income school", In Proceedings of the 14th international conference on Human-computer interaction with mobile devices and services, ACM, (2012), pp. 441-450.

[10] Jones and Marsden, "Mobile Technology Design from Advanced Interaction Design", (2006).

[11] "Mobile learning pilot project report in Nigeria", retrieved from www.yaraduacentre.org/filed/mlearning April 2015, (2013), pp. 1-24.

[12] L. F. Motiwalla, "Mobile learning: A framework and evaluation", Computers \& Education, vol. 49, no. 3, (2007), pp. 581-596.

[13] Naismith and Corlett, "Mobile Learning and Distance Learning", Journal of Computer Assisted Learning, vol. 20, (2006) spp. 399-409.

[14] D. Oblinger, J. L. Oblinger and J. K. Lippincott, "Educating the net generation", Boulder, Colo.: EDUCAUSE, c2005. 1 (various pagings): illustrations.

[15] A. Syvanen, R. Beale, M. Sharples, M. Ahonen and P. Lonsdale, "Supporting pervasive learning environments: adaptability and context awareness in mobile learning", In IEEE International workshop on wireless and mobile technologies in education (WMTE'05), IEEE, (2005), pp. 3.

[16] B. Yan, S. Mao and L. Ruan, "Notice of Retraction Research on E-Learning and its related issues", In Computer Science and Information Technology (ICCSIT), 2010 3rd IEEE International Conference on IEEE, vol. 8, (2010), pp. 331-334.

[17] J. Y. K. Yau and M. Joy, "An adaptive context-aware mobile learning framework based on the usability perspective”, International Journal of Mobile Learning and Organisation, vol. 4, no. 4, pp. 378-390. 
International Journal of Multimedia and Ubiquitous Engineering

Vol.12, No.2 (2017) 